\title{
Percutaneous Coronary Intervention versus Coronary Artery Bypass Grafting for Diabetics with Multivessel Coronary Artery Disease: The Korean Multicenter Revascularization Registry (KORR)
}

This study was designed to assess the relative merits of percutaneous coronary intervention $(\mathrm{PCl})$ and coronary artery bypass grafting (CABG) in multivessel coronary artery disease (MVCAD), particularly for Korean diabetics. Among 3,279 patients with MVCAD who were recommended for revascularization were enrolled from nine centers in Korea, 2,154 were selected after statistical adjustments for the disparities between two groups. Survival rates were not significantly different for three years between two groups. Among diabetic patients, the three-year mortality rate in $\mathrm{PCl}$ group was 1.9-fold higher than that of $\mathrm{CABG}$ group, although it was not statistically significant (PCI 19.8\%, CABG 11.4\%, $p=0.14)$. The three-year mortality rate was similar between the two groups in non-diabetics (PCI 8.3\%, CABG 10.0\%, $p=0.50$ ). The 30-day rate of cerebrovascular event was higher in CABG group, for both diabetic (CABG 3.6\%, PCl 0.0\%, $p<0.001$ ) and non-diabetic patients (CABG $2.4 \%, \mathrm{PCl}$ $0.0 \%, p<0.001)$. Short- and long-term revascularization rates were higher in $\mathrm{PCl}$ group than in CABG group. As a conclusion, this Korean registry demonstrates that $\mathrm{PCl}$ was associated with comparable survival rates and lower short-term morbidity, but a greater requirement for repeated revascularization compared with CABG in Korean diabetics.

Key Words : Angioplasty, Transluminal, Percutaneous Coronary; Coronary Artery Bypass; Diabetes Mellitus; Long-term Risk; Myocardial Ischemia
Hyeon-Cheol Gwon, Seung Hee Choi, Byung-ll William Choi*, Seung Yun Cho', Young Moo Ro , Won Ro Lee ${ }^{\S}$, for the KORR Investigators

Samsung Medical Center, Sungkyunkwan University School of Medicine, Seoul; Ajou University Hospital*, Suwon; Yonsei University Severance Hospital', Seoul; Korea University Hospital|, Seoul; "lsan Baik Hospital ${ }^{\$}$ Inje University, Ilsan, Korea

Received : 20 July 2004

Accepted : 29 November 2004

Address for correspondence

Won-Ro Lee, M.D.

Cardiac and Vascular Center, Ilsan Baik Hospital,

2240 Daewha-dong, Ilsan-gu, Goyang 411-706, Korea Tel : +82.31-910-7500, Fax : +82.31-913-5095

E-mail : wonrolee@ilsanbaik.ac.kr

${ }^{*}$ This study was supported by an unrestricted grant from the Korean Society of Circulation.

\section{INTRODUCTION}

Previous randomized studies have demonstrated that coronary artery bypass grafting $(C A B G)$ was associated with fewer episodes of angina, less requirement for repeated revascularization, but similar rates of death or myocardial infarction (MI) compared with percutaneous coronary intervention (PCI) (1-7). The Bypass Angioplasty Revascularization Investigation (BARI) study reported a better long-term survival rate in the CABG group for diabetic patients (8). However, those studies were performed in the pre-stent era and are therefore not representative of currently available technologies. The use of stents for percutaneous coronary artery intervention decreases acute complications, late restenosis, and the requirement for repeated revascularization $(9,10)$. Recently, an Argentinian randomized study showed that percutaneous coronary stent implantation was superior to $C A B G$ in terms of both survival and MI (11). However, recent American and European trials reported that $C A B G$ was associated with a similar survival rate and stroke- or MI-free survival as PCI $(12,13)$. Many studies are underway to clarify this issue. In Asia, however, studies comparing CABG and PCI are rare.

The Korean Multicenter Revascularization Registry (KORR) is a retrospective registry with physician-guided selection of treatment. This study was designed to assess the relative merits of PCI versus CABG in the post-stent era in multivessel coronary artery disease (MVCAD), particularly for diabetic patients.

\section{MATERIALS AND METHODS}

\section{Study design}

This study is in compliance with human studies committees in our hospital and Food and Drug Administration guidelines. For the study was designed as a retrospective registry of PCI and CABG, the distribution of baseline characteristics was not comparable between the two groups. We adjusted the distribution of several risk factors that were found to be important for clinical events, as described below. 


\section{Screening process}

Patients with two- or three-vessel coronary artery disease who underwent elective PCI or CABG between January 1995 and December 2000 in one of nine centers in Korea were enrolled in this registry. Patients with stable angina, acute coronary syndrome (ACS), acute myocardial infarction (AMI), or silent myocardial ischemia were included. Patients with cardiogenic shock, AMI indicated for primary PCI, concomitant valve surgery, a history of CABG, or mechanical complications such as ventricular septal defect, myocardial free-wall rupture, or mitral regurgitation, were excluded. Patients with significant left main disease were also excluded, to reduce the disparity in disease severity between the CABG and PCI groups. A total of 3,279 patients were included: 1,182 treated with CABG and 2,097 with PCI.

\section{$\mathrm{CABG}$ and $\mathrm{PCI}$ techniques}

CABG was performed with standard surgical techniques. Complete revascularization was attempted whenever possible, using arterial conduit or saphenous vein grafts. PCI was also performed using standard techniques. Patients were treated with aspirin (100-300 mg daily) $24 \mathrm{hr}$ before the procedure. Ticlopidine (500 mg daily) or cilostazol (500 mg daily) was given when stent implantation was planned, and continued for at least two weeks after stent implantation. Intravenous heparin was used to maintain an activated clotting time of more than $300 \mathrm{sec}$ during the procedure. The use of abciximab was limited to $0.8 \%$. Stents were used for either bail-out or

Table 1. Risk factors and odds ratios for MACE for the total population by multivariate logistic regression analysis. $\mathrm{PCl}$, old age, diagnosis of ACS or AMI, the presence of treated diabetes, LVEF $\geq 50 \%$, CVE history, and significant proximal LAD lesion were associated with a higher risk of MACE

\begin{tabular}{|c|c|c|c|c|c|c|}
\hline & \multicolumn{2}{|c|}{30 day MACE } & \multicolumn{2}{|c|}{1 yr MACE } & \multicolumn{2}{|c|}{3 yr MACE } \\
\hline & OR & $p$-value & OR & $p$-value & OR & $p$-value \\
\hline $\mathrm{PCl}$ & 1.18 & 0.52 & 3.48 & $<0.001$ & 4.39 & $<0.001$ \\
\hline Female & 1.49 & 0.14 & 0.99 & 0.95 & 1.17 & 0.28 \\
\hline Age $\geq 65 \mathrm{yr}$ & 1.65 & 0.024 & 1.32 & 0.010 & 1.46 & 0.002 \\
\hline ACS & 1.42 & 0.18 & 1.36 & 0.009 & 1.35 & 0.018 \\
\hline AMI & 2.34 & 0.008 & 1.44 & 0.021 & 1.34 & 0.093 \\
\hline Three-vessel disease & 1.23 & 0.36 & 1.06 & 0.62 & 1.03 & 0.82 \\
\hline Treated diabetes (\%) & 1.34 & 0.21 & 1.13 & 0.32 & 1.58 & 0.001 \\
\hline Smoking & 1.73 & 0.035 & 0.90 & 0.38 & 1.11 & 0.42 \\
\hline LVEF $\geq 50 \%$ (\%) & 0.65 & 0.071 & 0.75 & 0.020 & 0.67 & 0.005 \\
\hline CVE history & 2.54 & 0.001 & 1.53 & 0.011 & 1.59 & 0.014 \\
\hline Ml history & 1.59 & 0.071 & 1.06 & 0.69 & 1.99 & 0.92 \\
\hline Proximal LAD & 1.28 & 0.27 & 1.44 & 0.001 & 1.42 & 0.003 \\
\hline
\end{tabular}

MACE, major adverse cardiovascular event; OR, odds ratio; $\mathrm{PCl}$, percutaneous coronary intervention; ACS, acute coronary syndrome; AMI, acute myocardial infarction; LVEF, left ventricular ejection fraction; CVE, cerebrovascular event; MI, myocardial infarction; proximal LAD, significant lesion in the proximal left anterior descending artery. elective procedures.

\section{Adjustment of disparities in the distribution of prognostic factors}

Compared to CABG group, PCI group showed significantly higher proportion of patients with old age (age $\geq 65 \mathrm{yr}$ ), clinical diagnosis of AMI, normal left ventricular function. The clinical diagnosis of ACS, treated diabetes (diabetes currently treated with oral hypoglycemic drugs or insulin), and history of smoking, previous PCI, and previous cerebrovascular event (CVE) history were significantly less frequent in PCI group, respectively. Coronary angiogram showed significantly lower proportion of 3-vessel disease and proximal LAD lesion in PCI group, too. Risk factors for major adverse cardiac events (MACE) with the corresponding odds ratios are listed in Table 1. MACE was defined as death, myocardial infarction (MI), revascularization, or CVE.

Statistical adjustments were required to control for disparities in the distribution of independent prognostic factors between the PCI and CABG groups. Matched variables in-

Table 2. Clinical and angiographic characteristics of patients after matching six variables (marked as ${ }^{*}$ ). The numbers of patients with risk factors are similarly adjusted in the $\mathrm{CABG}$ and $\mathrm{PCl}$ groups after the matching process

\begin{tabular}{|c|c|c|c|c|c|c|}
\hline & \multicolumn{3}{|c|}{ Non-DM group } & \multicolumn{3}{|c|}{ DM group } \\
\hline & CABG & $\mathrm{PCl}$ & $p$-value & CABG & $\mathrm{PCl}$ & $p$-val \\
\hline Fema & 23.9 & 27.1 & 0.186 & 35.8 & 35.6 & .801 \\
\hline Age & & 35.9 & & 35.3 & 37.8 & \\
\hline & $\begin{array}{c}60.8 \pm \\
0.4\end{array}$ & $\begin{array}{c}61.0 \pm \\
0.3\end{array}$ & & $\begin{array}{c}61.9 \pm \\
0.6\end{array}$ & $\begin{array}{c}62.2 \pm \\
0.5\end{array}$ & 0.650 \\
\hline $\mathrm{ACS}$ & 56.1 & 53.4 & 24 & 56.7 & & .287 \\
\hline $\mathrm{Vl}$ & & & & & & \\
\hline yp & & & & 62.2 & & 205 \\
\hline & & 42.8 & 01 & 48.8 & & .001 \\
\hline & & & 006 & & & 0.27 \\
\hline LVEF & $\begin{array}{c}55.1 \pm \\
0.5\end{array}$ & $\begin{array}{c}57.7 \pm \\
0.4\end{array}$ & 0.015 & $\begin{array}{c}54.5 \pm \\
0.9\end{array}$ & $\begin{array}{c}53.5 \pm \\
0.8\end{array}$ & 0.456 \\
\hline $\mathrm{V} F F=$ & 78.3 & 77.4 & 0.707 & 69.7 & 69.6 & 0.988 \\
\hline & 17.2 & 11.7 & 0.004 & 15.4 & 1.0 & 0.125 \\
\hline CVE & 8.7 & 8.6 & 0.951 & 11.4 & 3.4 & 0.498 \\
\hline Ml hist & 24.6 & 16.4 & $<0.001$ & 25.9 & 15.6 & 0.003 \\
\hline PVD h & 5.9 & 4.3 & 0.168 & 7.5 & 6.3 & 0.603 \\
\hline $\begin{array}{r}\text { Three-ve } \\
\text { diseas }\end{array}$ & 67.2 & 29.9 & $<0.001$ & 72.6 & 32.9 & $<0.001$ \\
\hline Lesion & $\begin{array}{l}4.0 \pm \\
0.1\end{array}$ & $\begin{array}{l}3.0 \pm \\
0.0\end{array}$ & $<0.001$ & $\begin{array}{l}4.2 \pm \\
0.1\end{array}$ & $\begin{array}{l}3.2 \pm \\
0.1\end{array}$ & 0.001 \\
\hline & 44.1 & 42.6 & & 39.8 & 42.7 & 0.497 \\
\hline LAD intervention (\%) & 96.1 & 51.8 & $<0.001$ & 96.5 & 53.2 & $<0.00$ \\
\hline
\end{tabular}

*Variables for which adjustments were made. CABG, coronary artery bypass graft surgery; $\mathrm{PCl}$, percutaneous coronary intervention; $\mathrm{DM}$, treated diabetes; ACS, acute coronary syndrome; AMI, acute myocardial infarction; FHx of CAD, family history of coronary artery disease; LVEF, left ventricular ejection fraction; CVE, cerebrovascular event; MI, myocardial infarction; PVD, peripheral vascular disease; proximal LAD, significant lesion in the proximal left anterior descending artery. 
cluded old age (age $\geq 65 \mathrm{yr}$ ), clinical diagnosis (ACS or AMI), normal left ventricular function, CVE history, and the presence of a significant lesion in the proximal left anterior descending artery. The presence of diabetes was not matched because we intended to evaluate the impact of diabetes on clinical outcome, according to the two treatment modalities. A total of 2,154 patients were selected for the statistically adjusted population. The clinical and angiographic characteristics of the selected patients are listed in Table 2. CABG and PCI groups were compared for the matched population.

\section{Statistical analysis}

Results are presented as means \pm standard errors of the means. A $\chi^{2}$ test was used to determine the significant differences in categorical variables. For comparison of continuous variables, an unpaired t-test was used. For continuous variables with a distribution other than a normal distribution, a Wilcoxon two-sample test was used. Multivariate logistic regression analysis was performed to identify independent prognostic factors. A log-rank test was used for the comparison of Kaplan-Meier survival curves between groups. All tests were two-tailed, and a $p$-value $\leq 0.05$ was considered to be statistically significant.

Table 3. Clinical event rate in the CABG and PCI groups. Survival rate was similar between two groups. The 30-day incidence of CVE was significantly higher in the CABG group. Long-term risk of MACE was higher after $\mathrm{PCl}$, mainly due to the higher risk of revascularization

\begin{tabular}{|c|c|c|c|c|}
\hline & & $\begin{array}{c}\text { CABG } \\
(\mathrm{N}=661)\end{array}$ & $\begin{array}{c}\mathrm{PCl} \\
(\mathrm{N}=1,493)\end{array}$ & $p$-value \\
\hline \multirow{4}{*}{ Death (\%) } & 30 day & 1.4 & 0.8 & 0.20 \\
\hline & $1 \mathrm{yr}$ & 3.8 & 3.0 & 0.37 \\
\hline & $2 \mathrm{yr}$ & 6.5 & 5.3 & 0.40 \\
\hline & $3 \mathrm{yr}$ & 10.4 & 10.7 & 0.92 \\
\hline \multirow[t]{4}{*}{ Death, MI, CVE (\%) } & 30 day & 4.0 & 1.3 & $<0.001$ \\
\hline & $1 \mathrm{yr}$ & 7.8 & 5.8 & 0.13 \\
\hline & $2 y r$ & 12.0 & 10.5 & 0.43 \\
\hline & $3 \mathrm{yr}$ & 18.8 & 18.9 & 0.97 \\
\hline Ml (\%) & 30 day & 0.2 & 0.2 & 0.78 \\
\hline CVE (\%) & 30 day & 2.8 & 0.1 & $<0.001$ \\
\hline \multirow[t]{4}{*}{ Revascularization (\%) } & 30 day & 0.3 & 2.3 & $<0.001$ \\
\hline & $1 \mathrm{yr}$ & 4.0 & 21.9 & $<0.001$ \\
\hline & $2 \mathrm{yr}$ & 6.8 & 33.3 & $<0.001$ \\
\hline & $3 y r$ & 11.2 & 49.9 & $<0.001$ \\
\hline \multirow[t]{4}{*}{ MACE (\%) } & 30 day & 4.0 & 3.1 & 0.29 \\
\hline & $1 \mathrm{yr}$ & 10.5 & 24.3 & $<0.001$ \\
\hline & $2 \mathrm{yr}$ & 16.8 & 37.0 & $<0.001$ \\
\hline & $3 y r$ & 25.6 & 53.9 & $<0.001$ \\
\hline
\end{tabular}

CABG, coronary artery bypass graft surgery; $\mathrm{PCl}$, percutaneous coronary intervention; $\mathrm{MI}$, myocardial infarction; CVE, cerebrovascular event; MACE, major adverse cardiovascular event.

\section{RESULTS}

\section{Overall results}

The average follow-up period was $2.1 \pm 1.6 \mathrm{yr}$ (range, $0-6.6$ yr). Eighty-four per cent of patients were followed-up for more than one year, and $47.1 \%$ for more than three years.

There was no significant difference between the short- and long-term mortality rates in the PCI and CABG groups up to three years. The long-term incidence of morbidity (death, MI, or CVE) was also not significantly different between groups, but the 30-day incidence was significantly higher in the CABG group (CABG $4.0 \%$, PCI $1.3 \%, p=0.001$ ), which was mainly due to a higher incidence of CVE in the CABG group (CABG 2.8\%, PCI 0.1\%, $p<0.001$; Table 3, Fig. 1). However, the incidence of MACE (death, MI, CVE, or revascularization) was significantly higher in the PCI group than in CABG group after one year, which was due to a higher incidence of revascularization in the PCI group.

\section{Influence of diabetes on clinical outcome}

Of the matched population, 693 patients (32.2\%) had a history of diabetes and 566 patients (26.3\%) were being treated with oral hypoglycemics or insulin (treated diabetic patients) at the time of revascularization. In non-treated diabetics, 83.7 $\%$ of patients were followed-up for more than a year, and 47.9 $\%$ for more than $3 \mathrm{yr}$, and in treated diabetics, $83.0 \%$ for more than a year and $44.9 \%$ for more than $3 \mathrm{yr}$.

Mortality rates were similar between the CABG and PCI groups, for both the treated and non-treated diabetic patients (Table 4, Fig. 2). In treated diabetic patients, the 30-day mortality rate was 2.22-fold higher, whereas the three-year mortality rate was 1.92-fold lower in the CABG group, although these differences were not statistically significant. In nonetreated diabetic patients, however, the odds ratio was virtually not changed over three years. Treated diabetes was associated with higher three-year mortality only in the PCI group (non-treated diabetes $8.3 \%$, treated diabetes $19.8 \%$, odds ratio $=2.74, p=0.002$ ).

The 30-day incidence of morbidity (death, MI, or CVE) in the CABG group was significantly higher than in the PCI group, for both non-treated and treated diabetics (non-treated diabetics: CABG 3.3\%, PCI 1.0\%, $p=0.002$; treated diabetics: CABG $5.6 \%$, PCI $2.0 \%, p=0.026$ ), mainly due to a higher incidence of CVE in the CABG group. The 30-day incidence of CVE was significantly higher in both non-treated and treated diabetics (non-treated diabetics: CABG 2.4\%, PCI $0.1 \%, p<0.001$; treated diabetics: CABG 3.6\%, PCI $0.0 \%, p<0.001)$.

CABG was preferable to PCI in terms of the risk of revascularization, for both non-treated and treated diabetic patients. Treated diabetes was a significant prognostic factor for threeyear revascularization (non-treated diabetes $46.9 \%$, treated 

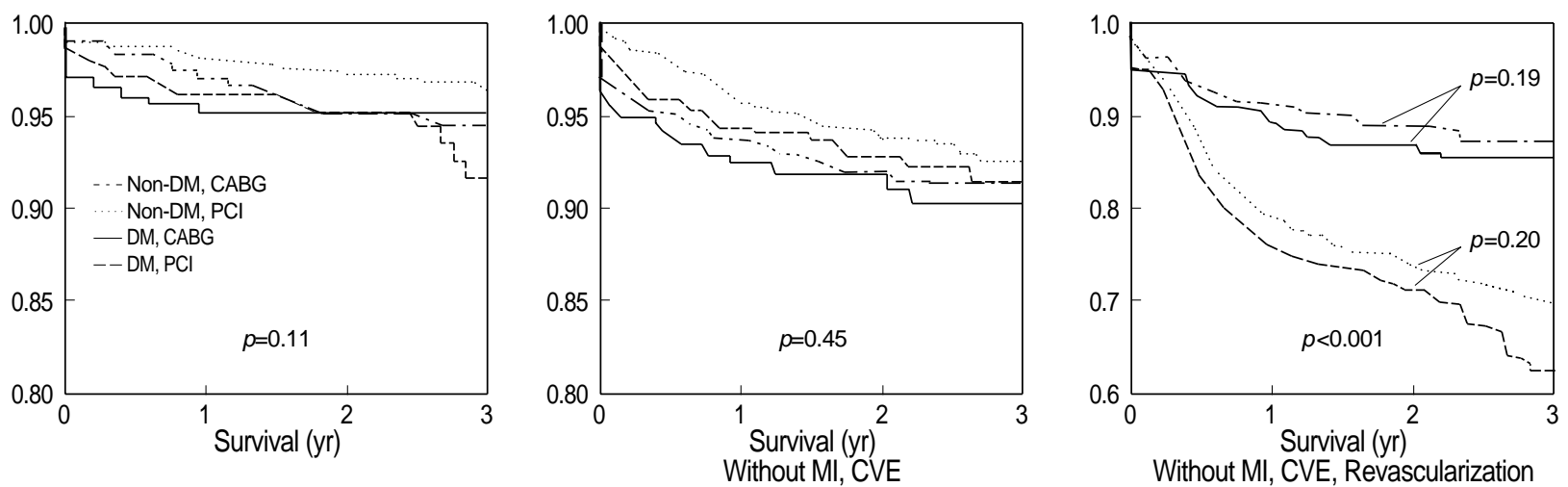

Fig. 1. Kaplan-Meier curve for cardiovascular event (CVE). Survival rates are similar for the two revascularization strategies. Long-term morbidity (death, Ml, or CVE) also dose not differ significantly, but the 30-day incidence of morbidity is significantly higher in the CABG group, mainly due to a higher incidence of CVE in that group. The infarct- or CVE-free survival rate without revascularization is much higher in the CABG group, due mainly to a lower revascularization rate.
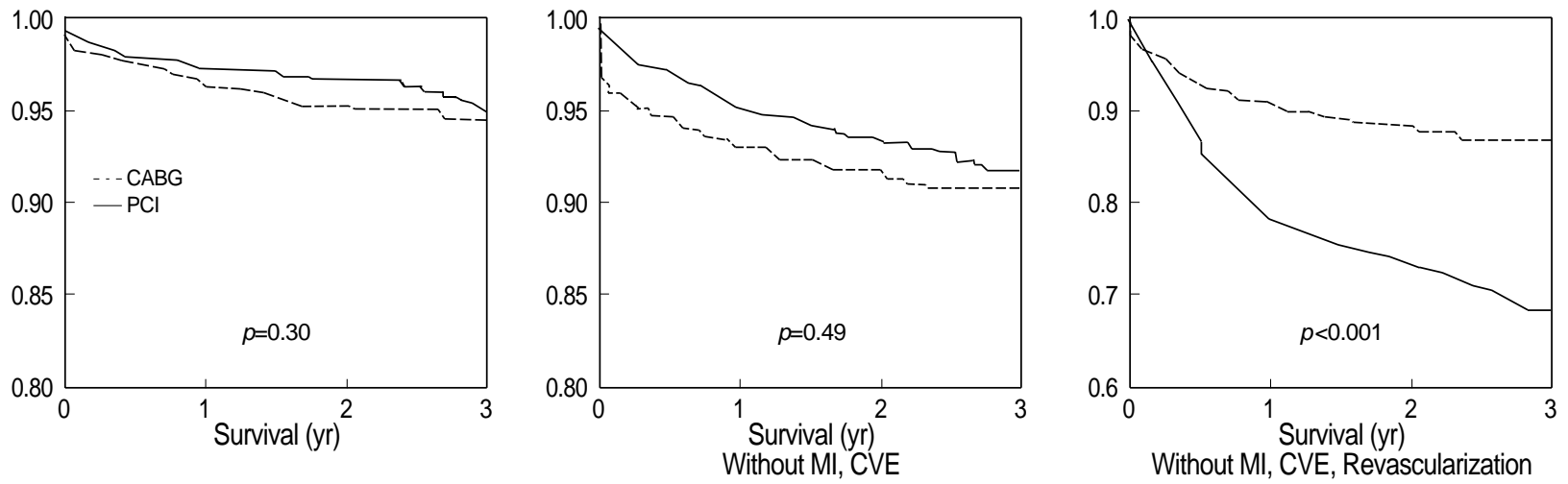

Fig. 2. Clinical outcomes according to diabetic status and revascularization strategy. Mortality and morbidity are similar after CABG or $\mathrm{PCl}$, both for treated diabetic and non-treated diabetic patients. For treated diabetic patients, however, the 30-day mortality rate is higher, whereas the three-year mortality rate is lower in the CABG group, although these differences are not statistically significant. The 30-day MI- or CVE-free survival rate is significantly higher in the CABG group due to the higher rate of CVE. MACE is significantly lower in the CABG group.
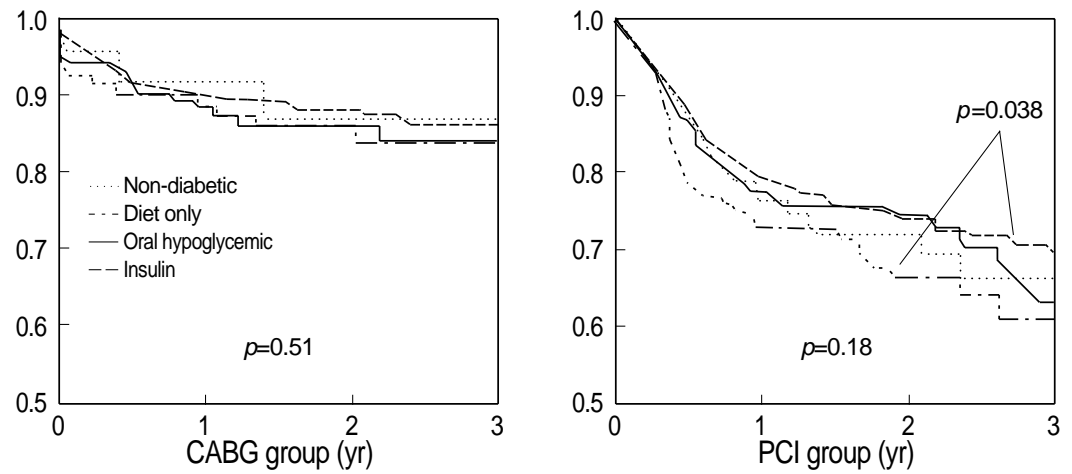

Fig. 3. Neither the mortality, morbidity, nor MACE rate is significantly different between the four diabetes treatment modality groups, in either the CABG or PCl groups. In the $\mathrm{PCl}$ group, treated diabetic patients had a higher risk of MACE.

diabetes $60.5 \%$, odds ratio $=1.29, p=0.003)$ and three-year MACE rate only in the PCI group (non-treated diabetes 50.9 $\%$, treated diabetes $62.2 \%$, odds ratio $=1.26, p=0.002)$. However, in CABG group, treated diabetes was not a significant risk factor for any event.

\section{MACE in diabetic subgroups within and between treatment} cohorts

None of the mortality, morbidity, or MACE rates differed significantly among the four diabetes treatment modality groups, either in the CABG or PCI groups (Fig. 3). Insulin- 
Table 4. Clinical outcomes in subgroups defined according to treatment modality and the presence of treated diabetes. Mortality rates were not significantly different after $\mathrm{PCl}$ or $\mathrm{CABG}$ for three years, although mortality was 1.9-fold higher in the PCI group compared with the CABG group. In non-diabetic patients, the mortality rate was similar for the two revascularization strategies for three years. Three-year mortality rates were significantly higher for diabetics than for non-diabetics only in the PCl group. The rate of death, $\mathrm{Ml}$ or CVE after 30 days was higher in the CABG group for diabetic and non-diabetic patients, as a result of the higher 30-day CVE rate. Short- and long-term revascularization was more frequent in the $\mathrm{PCl}$ group than in the $\mathrm{CABG}$ group

\begin{tabular}{|c|c|c|c|c|c|c|c|c|c|}
\hline & Non-D & M group & & & Non-DN & M grou & & & $\begin{array}{l}\text { value } \\
\text { n-DM } \\
\text { DM }\end{array}$ \\
\hline & CABG PCl & $\mathrm{OR}$ & $\begin{array}{c}p- \\
\text { value }\end{array}$ & CABG & à $\mathrm{PCl}$ & $\mathrm{OR}$ & $\begin{array}{c}p- \\
\text { value }\end{array}$ & $\mathrm{CABC}$ & $\mathrm{G} P C l$ \\
\hline Death ( & & & & & & & & & \\
\hline $30 D$ & 0.90 .7 & 0.75 & 0.64 & 2.5 & 1.2 & 0.45 & 0.23 & 0.095 & 50.35 \\
\hline $1 Y$ & 3.12 .5 & 0.80 & 0.55 & 5.4 & 4.5 & 0.82 & 0.66 & 0.20 & 0.12 \\
\hline $2 Y$ & $6.2 \quad 4.4$ & 0.70 & 0.27 & 7.1 & 8.1 & 1.15 & 0.75 & 0.74 & 0.069 \\
\hline $3 Y$ & $\begin{array}{ll}10.0 & 8.3\end{array}$ & 0.81 & 0.50 & 11.4 & 19.8 & 1.92 & 0.14 & 0.73 & 0.002 \\
\hline Death, I & MI, CVE(\%) & & & & & & & & \\
\hline $30 D$ & $3.3 \quad 1.0$ & 0.31 & 0.002 & 5.6 & 2.0 & 0.35 & 0.026 & 0.17 & 0.15 \\
\hline $1 Y$ & $7.0 \quad 5.5$ & 0.78 & 0.32 & 9.6 & 6.8 & 0.69 & 0.30 & 0.29 & 0.45 \\
\hline $2 Y$ & 11.59 .9 & 0.84 & 0.47 & 13.2 & 12.6 & 0.95 & 0.88 & 0.62 & 0.31 \\
\hline $3 Y$ & 17.317 .1 & 0.99 & 0.96 & 22.4 & 25.8 & 1.21 & 0.59 & 0.32 & 0.056 \\
\hline $\mathrm{Ml}(\%)$ & & & & & & & & & \\
\hline $30 \mathrm{D}$ & 0.20 .2 & 0.86 & 0.90 & 0.0 & 0.3 & - & 0.45 & 0.51 & 0.71 \\
\hline CVE (\% & & & & & & & & & \\
\hline $30 D$ & 2.40 .1 & $0.04<$ & $<0.001$ & 3.6 & 0.0 & - & $<0.001$ & 0.40 & 0.57 \\
\hline Revasc & sularization ( & & & & & & & & \\
\hline $30 D$ & $0.4 \quad 2.2$ & 5.15 & 0.013 & 0.0 & 2.3 & - & 0.034 & 0.36 & 0.93 \\
\hline $1 Y$ & 4.221 .1 & $6.14<$ & $<0.001$ & 3.7 & 24.6 & 3.61 & $<0.001$ & 0.79 & 0.21 \\
\hline $2 Y$ & 6.632 .3 & $6.76<$ & $<0.001$ & 7.2 & 36.6 & 7.45 & $<0.001$ & 0.82 & 0.24 \\
\hline $3 Y$ & 11.146 .9 & $7.10<$ & $<0.001$ & 11.5 & 60.5 & 11.6 & $<0.001$ & 0.91 & 0.003 \\
\hline MACE ( & (\%) & & & & & & & & \\
\hline $30 \mathrm{D}$ & $3.3 \quad 3.1$ & 0.93 & 0.81 & 5.6 & 3.2 & 0.55 & 0.17 & 0.17 & 0.92 \\
\hline $1 Y$ & 9.823 .4 & $2.81<$ & $<0.001$ & 12.2 & 27.2 & 2.68 & $3<0.001$ & 10.39 & 0.19 \\
\hline $2 Y$ & 16.025 .8 & $2.91<$ & $<0.001$ & 18.5 & 40.9 & 3.04 & $t<0.001$ & 0.59 & 0.16 \\
\hline $3 Y$ & 23.950 .9 & $3.21<$ & $<0.001$ & 29.3 & 64.2 & 4.32 & $<0.001$ & 0.32 & 0.003 \\
\hline
\end{tabular}

$\mathrm{CABG}$, coronary artery bypass graft surgery; $\mathrm{PCl}$, percutaneous coronary intervention; $\mathrm{DM}$, treated diabetics; $\mathrm{OR}$, odds ratio of the $\mathrm{PCI}$ group compared with the CABG group; 30D, 30-day; 1Y, one-year; $2 \mathrm{Y}$, two-year; $3 Y$, three-year; MI, myocardial infarction; CVE, cerebrovascular event; MACE, major adverse cardiovascular event.

treated diabetic patients, however, had a higher risk of MACE than non-diabetic patients in the PCI group $(p=0.038)$.

\section{Arterial graft vs. stent}

Stents were used in $68.5 \%$ of PCIs. Stent implantation was associated with reduced 1-yr death or MI risk (non-stent 7.1 $\%$, stent $3.6 \%, p=0.014)$ and reduced 30 -day revascularization rate (non-stent $3.6 \%$, stent $1.6 \%, p=0.02$ ). Arterial graft was performed in $92.1 \%$ CABGs. The left internal mammary artery was used in $91.1 \%$ of cases. In $14.2 \%$ of CABGs, only arterial grafts were used. In $23.0 \%$ of CABGs, surgical procedures were performed without a cardiopulmonary bypass pump. The arterial graft group showed a significantly lower three-year mortality rate (arterial graft $8.6 \%$, vein graft 21.6 $\%, p=0.016$ ) and a lower three-year MACE rate (arterial graft $23.2 \%$, vein graft $40.5 \%, p=0.017$ ) compared with the veingraft-only group.

To compare current therapeutic technologies, the rate of MACE was compared between the stent and arterial graft groups. Thirty-day revascularization was reduced in the stent group and did not differ significantly from that of the CABGwith-arterial-graft group. Otherwise, the results were similar to those of the total adjusted population.

\section{DISCUSSION}

This study is the first Korean multicenter registry that compares the long-term clinical outcomes of two currently used coronary revascularization strategies. Short- and long-term mortality rates did not differ significantly between the PCI and CABG groups after up to three years of follow-up. Early morbidity was higher in the CABG group than in the PCI group, due to a higher rate of CVE. Three-year event-free survival was much higher in the CABG group than in the PCI group, due to an increased rate of revascularization in the PCI group.

Short- and long-term mortality rates did not differ significantly between the PCI and CABG groups for diabetic or non-diabetic patients, although there was a trend in the PCI group towards an increased three-year mortality rate among diabetics. In the PCI group, diabetes was associated with significantly higher mortality and MACE rates at three years, in contrast to the CABG group in which the two cohorts did not differ. In a separate analysis of arterial graft vs. stent, the short- and long-term outcomes were similar to those of the total adjusted population.

Our current practice of selecting the treatment modality for patients with MVCAD is based on the results of many prior randomized trials (1-7). The BARI study is representative of the pre-stent era. It demonstrated that CABG was more successful than PCI in terms of the seven-year survival rate, mainly due to the beneficial effects of CABG for diabetic patients. The seven-year survival rate was $65.5 \%$ for PCI and $80.6 \%$ for CABG in the diabetic group $(p=0.003)$ (8). In non-diabetics, there was no difference in survival after PCI or CABG. In the Emory Angioplasty versus Surgery Trial (EAST), treated diabetics showed similar mortality rates to non-treated diabetics until the three-year follow-up. However, the curves began to diverge after five years, and by eight years, mortality rates were better after surgery, although the differences were not statistically significant (14). The Northern New England Cardiovascular Disease Study also showed that diabetics treat- 
ed with PCI had mortality rates significantly higher than patients undergoing CABG (hazard ratio $=1.49, p=0.037$ ) (15). Mortality risk tended to increase more among patients with three-vessel disease (hazard ratio $=2.02, p=0.038$ ) than among patients with two-vessel disease (hazard ratio $=1.33$, $p=0.21$ ).

In contrast, the BARI registry showed that seven-year survival was similar after PTCA or CABG $(85.8 \%$ for PCI, 86.1 $\%$ for CABG, $p=0.66$ ) (16). Even among diabetics, PTCA and CABG showed similar seven-year survival rates $(74.0 \%$ for PCI, $74.0 \%$ for CABG). The results of the Coronary Angioplasty versus Bypass Revascularization Investigation (CABRI) trial also indicated that there was no significant difference in four-year mortality rates between patients randomized to either PCI or CABG strategies, in either diabetic or non-diabetic patients, although diabetes was a significant risk factor for mortality (17). Duke University database also noted similar long-term outcomes after either PCI or CABG for diabetic patients with multivessel disease (18).

Since the completion of these early major trials, significant technological advances have been made in the field of coronary revascularization, in both PCI and CABG. Stent implantation is associated with greater clinical success, and a significantly lower long-term revascularization rate $(9,10)$. Recent PCI vs. CABG studies in the management of MVCAD have utilized advanced technologies including stent implantation. The Argentine randomized study (ERACI-II) also showed a better survival rate with PCI than with CABG after 30 days and at one year (11). However, the Arterial Revascularization therapies Study (ARTS) and the Angina With Extremely Serious Operative Mortality Evaluation (AWESOME) study demonstrated similar mortality rates after $2-3$ yr for PCI and CABG $(12,13)$. Repeat revascularization rates seemed to improve in the stent group compared with the rates for the balloon groups of previous studies. However, rates of revascularization were still significantly higher than those of the CABG group, particularly for treated diabetics.

The prevalence of diabetes has been increasing explosively in Korea, as in other eastern societies (19). This is also true for mortality from coronary artery disease, which parallels the prevalence of diabetes (20). Treatment for coronary artery disease in diabetic patients is still not satisfactory in terms of long-term mortality and morbidity. Despite many multicenter trials, the most appropriate selection of a revascularization strategy remains to be established, particularly in diabetic patients with multivessel disease. Moreover, in Asian countries, studies comparing long-term outcomes of PCI and CABG in patients with advanced coronary artery disease are rare.

In Korea, Sim et al. reported similar early clinical outcome and higher long-term target lesion revascularization rate in the coronary stent group compared to coronary artery bypass group in single center registry of 160 patients (30.5 months follow-up: stent group $18.9 \%$, bypass group $5.7 \%, p<0.005$ ) (21). This Korean registry study will increase our understand- ing of the current situation and the outcomes associated with revascularization procedures in this region of the world.

KORR showed similar short- and long-term mortality rates for the two therapeutic modalities. These results are consistent with most previous comparative studies on PCI vs. CABG in the management of MVCAD. Similar survival rates were observed for both diabetic and non-diabetic patients. This finding is at variance with the BARI trial, but is similar to the results of the ARTS (22) and BARI registry. In the ERACI II study, the 30-day mortality rate was significantly higher in the $\mathrm{CABG}$ group than in the PCI group, due to the high mortality in the CABG group (PCI $0.9 \%$, CABG $5.7 \%, p=$ $0.013)$, which is partly attributable to the high proportion of patients with ACS in this study (11). In our data, however, the 30-day mortality rate of patients with ACS was less than $2.0 \%$ in both revascularization groups (CABG $1.1 \%$, PCI $0.3 \%, p=0.081$ )

Our data indicate that the early morbidity rate may be higher in the CABG group than in the PCI group. In the ARTS, the risk of MI or CVE was similar in the two groups (13). However, in KORR, the 30-day CVE risk was significantly lower in the PCI group. The incidence of CVE in KORR was lower than in the ARTS (KORR stent group, 30 days CVE, $0.0 \%$, and one-year CVE, 0.6\%; ARTS, one-year CVE, $1.5 \%$ ). The rate of CVE in this study was similar to that of the PCI group in the ERACI II trial (30 days CVE, 0.0\%) (11). Although the repeat revascularization rate after PCI was higher than after $\mathrm{CABG}$, the rate difference between diabetics and non-diabetics in KORR was less pronounced than in the ARTS study.

When considering the relative merits of the two revascularization techniques in the management of MVCAD in the post-stent era, the two techniques seem equivalent in terms of survival. However, CABG appears to be superior to PCI insofar as the requirements for repeat revascularization is lower.

Treated diabetes was a risk factor for long-term mortality only in the PCI group, but the relative advantages and disadvantages of CABG compared with PCI did not differ markedly between diabetic and non-diabetic patients in this study. The survival benefit of CABG over PCI for diabetic patients has been demonstrated only in studies with longer-term follow-ups than that used in this study. The follow-up period was less than three years in several recent studies, including ERACI II, ARTS, and AWESOME. In the EAST trial, the benefits of CABG for diabetics were demonstrated only after five years. The survival curves for diabetic patients of this study began to diverge after two years and showed a mortality rate in the PCI group almost twofold higher than that of the CABG group, although the difference was not statistically significant.

A common problem of long-term comparative studies of PCI vs. CABG is that the results may become obsolete even before publication, due to the speed of technological development and advancement. Recently, drug-eluting stents have 
shown very promising results on restenosis $(23,24)$. The restenosis rate following stenting may be lowered further in the future. Therefore, PCI with drug-coated stents may achieve similar or even better outcomes than those of CABG, and comparative assessments of drug-coated stent versus CABG may be necessary in the near future.

One of the limitations of this study is that KORR is a retrospective and non-randomized study with physician-guided selection of treatment. Although the differences measured between the two treatment groups were controlled, this statistical adjustment can be imperfect. Another important limitation is that the long-term follow-up rate is relatively low compared to previous western studies. Therefore, the twoor three-year event rate may be even less reliable. The third limitation is that the stent implantation rate was only $68.5 \%$, which is relatively low considering current practice of PCI in Korea, because the patients of this study had been recruited before year 2001. Moreover, drug-eluting stents have been already on the market for more than a year and dramatically changed the revascularization strategy in the patients with multi-vessel disease. The difficulty in keeping up the current practice pattern always has been one of the major limitations of large trials or registries with long term follow-up. The contemporary techniques should be considered to interpret and apply this data to current practice in Korea.

As a conclusion, in this multicenter Korean registry, we found that survival rates were similar after PCI and CABG for treated diabetics as well as for the total population. Compared with CABG, PCI was associated with a lower incidence of short-term morbidity but with a greater requirement for repeated revascularization, particularly in treated diabetics.

\section{ACKNOWLEDGMENTS}

The KORR participants were: from the Samsung Medical Center/Sungkyukwan University, Won Ro Lee and HyeonCheol Gwon; from Aju University Hospital, Byung-il William Choi, MD; from the Asan Medical Center/Ulsan University, Seung-Jung Park, MD; from Chonnam National University Hospital, Myung Ho Jeong, MD; from Dong-A University Hospital, Moo Hyun Kim, MD, and Jong Soo Woo, MD; from Incheon Kil Medical Center/Kacheon University, Eak Kyun Shin, MD; from Korea University Hospital, Young Moo Ro, MD; from Seoul National University Hospital, Young-Bae Park, MD, and Ki-Bong Kim, MD; and from Yonsei University Hospital, Seung Yun Cho, MD, and Byung-Chul Chang, MD.

\section{REFERENCES}

1. Patil CV, Nikolsky E, Boulos M, Grenadier E, Beyar R. Multivessel coronary artery disease: current revascularization strategies. Eur
Heart J 2001; 22: 1183-97.

2. Rodriguez A, Boullon F, Perez-Balino N, Paviotti C, Liprandi MI, Palacios IF. Argentine randomized trial of percutaneous transluminal coronary angioplasty versus coronary artery bypass surgery in multivessel disease (ERACI): in-hospital results and 1-year follow-up. J Am Coll Cardiol 1993; 33: 1060-7.

3. King SB 3rd, Lembo NJ, Weintraub WS, Kosinski AS, Barnhart HX, Kutner MH, Alazraki NP, Guyton RA, Zhao XQ. A randomized trial comparing coronary angioplasty with coronary bypass surgery. $N$ Engl J Med 1994; 331: 1044-50.

4. RITA Trial Participants. Coronary angioplasty versus coronary artery bypass surgery: the Randomized Intervention Treatment of Angina (RITA) trial. Lancet 1993; 341: 573-80.

5. CABRI Trial participants. Coronary Angioplasty vs. Bypass Revascularization Investigation (CABRI) results during the first year. Lancet 1995; 346: 1179-83.

6. Hamm CW, Reimers J, Ischinger T, Rupprecht HJ, Berger J, Bleifeld W. A randomized study of coronary angioplasty compared with bypass surgery in patients with symptomatic multivessel coronary disease. $N$ Engl J Med 1994; 331: 1037-43.

7. Carrie D, Elbaz M, Puel J, Fourcade J, Karouny E, Fournial G, Galinier M. Five-year outcome after coronary angioplasty versus bypass surgery in multivessel coronary disease. Circulation 1997; 96: III-II6.

8. Bypass Angioplasty Revascularization Investigation (BARI) Investigators. Comparison of coronary bypass surgery with angioplasty in patients with multivessel disease. N Engl J Med 1996; 335: 217-25.

9. Fischman DL, Leon MB, Baim DS, Schatz RA, Savage MP, Penn I, Detre K, Veltri L, Ricci D, Nobuyoshi M, Cleman M, Heuser R, Almond D, Teirstein PS, Fish RD, Colombo A, Brinker J, Moses J, Shaknovich A, Hirshfeld J, Bailey S, Ellis S, Rake R, Goldberg S. A randomized comparison of coronary-stent placement and balloon angioplasty in the treatment of coronary artery disease. N Engl J Med 1994; 331: 496-501.

10. Serruys PW, DeJaegere P, Kiemeneij F, Macaya C, Rutsch W, Heyndrickx G, Emanuelsson H, Marco J, Legrand V, Materne P, Belardi J, Sigwart U, Colombo A, Goy JJ, Van Den Heuvel P, Delcan J Morel M. A comparison of balloon-expandable-stent implantation with balloon angioplasty in patients with coronary artery disease. $N$ Engl J Med 1994; 331: 489-95.

11. Rodriguez A, Bernardi V, Navia J, Baldi J, Grinfeld L, Martinez J, Vogel D, Grinfeld R, Delacasa A, Garrido M, Oliveri R, Mele E, Palacios I, O'Neill W. Argentine randomized study: coronary angioplasty with stenting versus coronary bypass surgery in patients with multiple-vessel disease (ERACI II): 30-day and one-year follow-up results. J Am Coll Cardiol 2001; 37: 51-8.

12. Morrison DA, Sethi G, Sacks J, Henderson W, Grover F, Sedlis S, Esposito R, Ramanathan K, Weiman D, Saucedo J, Antakli T, Paramesh V, Pett S, Vernon S, Birjiniuk V, Welt F, Krucoff M, Wolfe W, Lucke JC, Mediratta S, Booth D, Barbiere C, Lewis D. Percutaneous coronary intervention versus coronary artery bypass graft surgery for patients with medically refractory myocardial ischemia and risk factors for adverse outcomes with bypass: a multicenter, randomized trial. Investigators of the Department of Veterans Affairs Cooperative Study \#385, the Angina With Extremely Serious Operative Mortality 
Evaluation (AWESOME). J Am Coll Cardiol 2001; 38: 143-9.

13. Serruys PW, Unger F, Sousa JE, Jatene A, Bonnier HJ, Schonberger JP, Buller N, Bonser R, van den Brand MJ, van Herwerden LA, Morel MA, van Hout BA. Comparison of coronary-artery bypass surgery and stenting for the treatment of multivessel disease. $N$ Engl J Med 2001; 344: 1117-24.

14. King SB III, Kosinski AS, Guyton RA, Lembo NJ, Weintraub WS. Eight-year mortality in the Emory Angioplasty versus Surgery Trial (EAST). J Am Coll Cardiol 2000; 35: 1116-21.

15. Niles NW, McGrath PD, Malenka D, Quinton H, Wennberg D, Shubrooks SJ, Tryzelaar JF, Clough R, Hearne MJ, Hernandez F Jr, Watkins MW, O'Connor GT; Northern New England Cardiovascular Disease Study Group. Survival of patients with diabetes and multivessel coronary artery disease after surgical or percutaneous coronary revascularization: results of a large regional prospective study. J Am Coll Cardiol 2001; 37: 1008-15.

16. Feit F, Brooks MM, Sopko G, Keller NM, Rosen A, Krone R, Berger $\mathrm{PB}$, Shemin R, Attubato MJ, Williams DO, Frye R, Detre KM. Longterm clinical outcome in the Bypass Angioplasty Revascularization Investigation Registry: comparison with the randomized trial. Circulation 2000; 101: 2795-802.

17. Kurbaan AS, Bowker TJ, Ilsley CD, Sigwart U, Rickards AF; On behlf of the CABRI Investigators (Coronary Angioplasty versus Bypass Revascularization Investigation). Difference in the mortality of the CABRI diabetic and nondiabetic populations and its relation to coronary artery disease and the revascularization mode. Am J Cardiol 2001; 87: 947-50.

18. Barsness GW, Peterson ED, Ohman EM, Nelson CL, DeLong ER,
Reves JG, Smith PK, Anderson RD, Jones RH, Mark DB, Califf RM. Relationship between diabetes mellitus and long-term survival after coronary bypass and angioplasty. Circulation 1997; 96: 2551-6.

19. The Korean Diabetes Association. Epidemiology of Diabetes. In: Diabetics. 2nd ed. Seoul, Korea: Koryo Medical Co., 1998: 23-4.

20. The Korean Diabetes Association. Epidemiology of Diabetes. In: Diabetics. 2nd ed. Seoul, Korea: Koryo Medical Co., 1998: 26-8.

21. Sim DS, Jeong MH, Kim W, Rhew JY, Yum JH, Kim JH, Ahn YK, Cho JG, Park JC, Ahn BH, Kim SH, Kang JC. Long-term clinical outcomes in diabetics after coronary artery bypass surgery and coronary stenting. Korean J Med 2003; 65: 160-7.

22. Abizaid A, Costa MA, Centemero M, Abizaid AS, Legrand VM, Limet RV, Schuler G, Mohr FW, Lindeboom W, Sousa AG, Sousa JE, van Hout B, Hugenholtz PG, Unger F, Serruys PW; Arterial Revascularization Therapy Study Group. Clinical and economic impact of diabetes mellitus on percutaneous and surgical treatment of multivessel coronary disease patients: insights from the Arterial Revascularization Therapy Study (ARTS) trial. Circulation 2001; 104: 533-8.

23. Sousa JE, Costa MA, Abizaid AC, Rensing BJ, Abizaid AS, Tanajura LF, Kozuma K, Van Langenhove G, Sousa AG, Falotico R, Jaeger J, Popma JJ, Serruys PW. Sustained suppression of neointimal proliferation by sirolimus-eluting stents: one-year angiographic and intravascular ultrasound follow-up. Circulation 2001; 104: 2007-11.

24. Morice MC, Serruys PW, Sousa JE, Fajadet J, Ban Hayashi E, Perin M, Colombo A, Schuler G, Barragan P, Guagliumi G, Molnar F, Falotico R: RAVEL study group. A randomized comparison of a sirolimus-eluting stent with a standard stent for coronary revascularization. N Engl J Med 2002; 346: 1773-80. 